\title{
Moving Special Collections Forward in an Age of Discovery: Themes from the ARL-CNI Forum
}

\author{
Lisa R. Carter, Head, Special Collections Research Center, \\ North Carolina State University Libraries and Visiting Program Officer \\ for the ARL Special Collections Working Group
}

his year's ARL-CNI Fall Forum, “An Age of Discovery: Distinctive Collections in the Digital Age," highlighted the opportunities special collections provide to engage users and realize the teaching, learning, and research missions of libraries and universities. Two hundred library directors and special collections librarians and archivists gathered at the Mayflower Hotel in Washington DC on October 15-16, 2009, to consider the value proposition of and innovation possibilities inherent in collections of rare books, archives, and other unique materials. The forum was based on the extensive and cumulative work of the ARL Special Collections Working Group and, specifically, its recent discussion report, Special Collections in ARL Libraries. ${ }^{1}$ Scholars, archivists, librarians and teachers spoke passionately about the value of special collections; how collaborations and integrating special collections into the enterprise can promote their use, garner them increased attention, and provide additional resources; how students develop life-long learning and research skills working with rare materials; and what issues are more prominent now that many of our distinctive collections are available, and even born, digitally. Presentations and recordings from the forum are available from the ARL Web site. ${ }^{2}$

Several themes recurred throughout the forum, suggesting areas for future exploration, effort, and emphasis, including:

1. Use Drives Special Collections Activity

2. Special Collections Are Central to the Academic Enterprise

3. Digital and Collaboration are Necessary 
These themes point to next steps the research library community must take to strategically address the needs of 21st-century researchers-students, faculty, and life-long learners-and connect them to our most unique collections.

\section{Use Drives Special Collections Activity}

Use as the driving force in the value proposition of collecting, maintaining, and providing access to special collections surfaced early in the forum and was reinforced repeatedly throughout. From that positioning, speakers articulated the impact that unique, rare, and primary resources are having on learners of every scholarly level by sharing innovative projects and examples from collections. Using engrossing examples as diverse as brilliant illuminated manuscripts, heart-wrenching human rights Web sites, fragmented Buddhist scrolls, and newly revealed Archimedes drawings, presenters addressed the critical matter of getting materials into the hands of users more quickly and in ways that promote dynamic and meaningful advancement of knowledge.

Speakers advocated rethinking strategies for resource allocation, processing and digitization workflows, and promoting special collections in the context of use. Mark Greene urged against "protective thinking" that leads to inefficient processing, highly selective digitization, and delays in expeditious discoverability by the widest audience, including $\mathrm{K}-12$ and undergraduate students alongside "qualified" researchers. G. Wayne Clough shared the Smithsonian's work to support a learning journey that starts before a visit to a collection, creates tangible memories during, and continues long after, suggesting that collections want to be "petted." Don Waters promoted framing the investment in special collections and archives in the context of scholarly objectives and improving the efficiency of research.

Several speakers provided evidence of how use is changing with the advancement of digital technologies. Now that digital delivery is an expectation, metadata must facilitate deep discovery and user contribution should be harnessed to enrich future research. In a Web 2.0 environment, special collections need to be findable at the surface of the Web, open for creative reuse and placed well within users' fluid virtual work spaces. Clough encouraged libraries to expose collections for the challenging, organic aggregations of knowledge that they are.

Increasingly, use can be leveraged to increase future research. Jacqueline Goldsby discussed her success with graduate student scholars working on the 


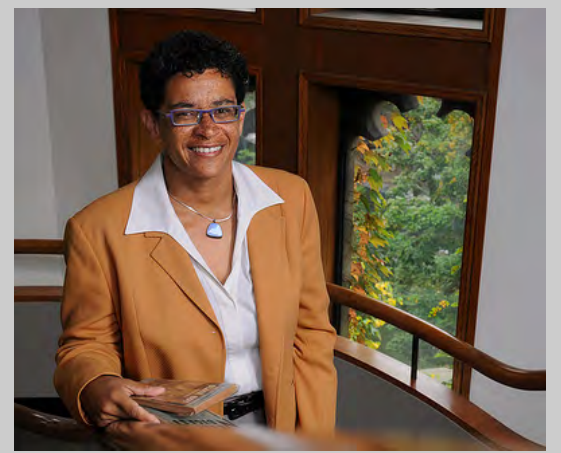

Listen to Jacqueline Goldsby on the value of a collective model of humanist inquiry that breaks down silos and enriches our understanding of mid-20th-century African American literary and cultural studies. [ 4 min.] http://www.arl.org/bm doc/rli-267goldsby.mp3

Photo: David Christopher

the Ethnography of the University project at the University of Illinois at Urbana-Champaign (UIUC) seed future study by depositing their output into the institutional repository. These projects show the added value of engaging students with special collections in a curricular context and illustrated Waters' observation that bringing users efficiently into processing streams requires solid infrastructure and scholar-friendly data-entry tools.

Summarizing various speakers' reflections on use, Alice Prochaska noted that special collections are not distinctive just because they are unique but also because of what their stewards do with them to promote use. Placing students and scholars at the center of the value proposition brings strategically built collections into alignment with the academic mission. Effective assessment methodologies can then drive advocacy and ensure allocation of resources in the broader university environment.

\section{Special Collections Are Central to the Academic Enterprise}

Throughout the forum, this call to align special collections with the core mission and activities of the research enterprise provided a revised perspective for addressing the challenges of engaging scholars and advocating for resources.

Several speakers explored aligning special collections with the teaching and learning mission of research institutions. Beginning with the first panel, Steve Nichols acknowledged that traditionally special collections have been viewed as "eccentric" and marginal to undergraduate education, but suggested that they should instead be seen as intimately aligned with the teaching, learning, and research directive of research universities. This exposure must be more than show and tell and integrated into "the fabric of the curriculum," as Barbara Rockenbach noted. The Boyer Commission report, Reinventing Undergraduate Education, ${ }^{3}$ was referenced by both Rockenbach and Shreeves, who argued that 
engaging students with primary sources supports inquiry-based learning, hands-on exploration of meaning, and inquisitive habits of mind. Rockenbach's experiences with advancing the use of special collections in the classroom highlighted the aggressive outreach to faculty that this requires and the importance of promoting special collections as teaching space.

Shreeves discussed UIUC's living-learning project, Ethnography of the University, which requires students to employ archival research in analyzing issues in the academic environment they inhabit. Shreeves noted that using archives and publishing in the institutional repository helps students better understand the implications of their original research and the modern research cycle, and that assessments show that students feel more engaged than they do in other class work. Greene described another successful approach in which innovative teaching grants from the American Heritage Center are given to faculty to build undergraduate courses around primary sources.

Alignment is not limited to fostering curricular engagement. The value of special collections can be greatly enhanced by engaging the learning concerns

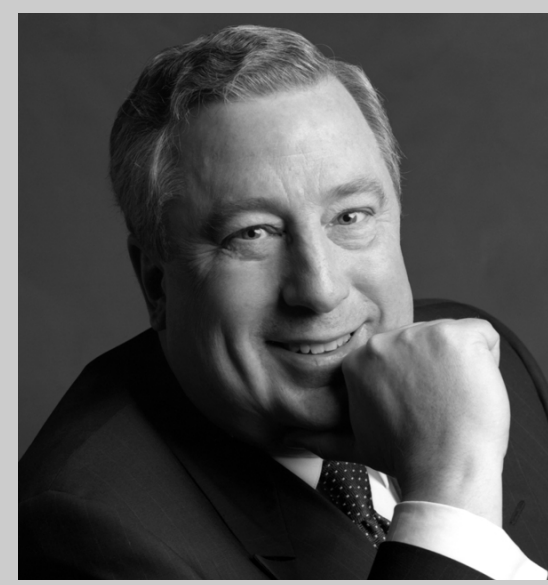

Listen to lan Wilson describe how special collections offer leadership opportunities in the e-world. [4 min.] http://www.arl.org/bm doc/rli-267-wilson.mp3 of broader communities. Special collections can provide intense personal connections for some users. Ian Wilson and Fred Heath reminded the audience that a broader constituency can play a key role in generating support for an institution's mission, whether that constituency is a group of genealogists or human rights advocates. Josh Greenberg gave the example of the unexpected turnout of hundreds of New Yorkers to the New York Public Library's Design by the Book debut video-screening party to learn about book arts. Clough spoke of reaching over 4,000 people through the Smithsonian's offering of free, educational, collection-oriented webinars. If the core mission of the research library is to advance knowledge, special collections play a critical role in advancing inquiry at a most basic level.

As special collections increasingly move to the center of the research library, activities and resources that increase their accessibility must be mainstreamed. Assets, skills, and talents across the institution can be leveraged to expose distinctive collections alongside other information resources. Speakers noted 
that permanent funding, along with requirements for collaboration, efficiency, and policy development must come from the top. Archivists and special collections librarians must constantly demonstrate alignment with the organizational mission, engage institutional colleagues and provide evidence of how less-compelling topics contribute to research, teaching, and learning. Ken Hamma specifically noted the slow, iterative nature of incorporating special collections into the enterprise, requiring persistent reframing of special collections in the context of institutional goals. The current financial environment precipitates the need to share models for integrating special collections into the main information-management and discovery workflows in the research library.

\section{Digital and Collaboration Are Necessary}

Special collections present opportunities for research libraries to enrich transformations affecting research and research-intensive institutions. Libraries and their special collections have a strong record of embracing the digital information environment and collaboration to support changing modes of research. Yet presenters urged that more attention be given to developing and ensuring sustainability and building solid infrastructure in both areas.

Speakers promoted the digitization of collections as key to connecting special collections with users, but quickly moved beyond the advantages of digital surrogates to the expanded options presented by the digital world. Collections can be transformed online; for example, providing access to details that cannot be seen with the naked eye and reuniting pieces of disparate collections virtually. Will Noel shared astonishing examples of digital transformation and rediscovery of unique items based on his work with the Archimedes Palimpsest and other projects at the Walters Art Gallery. Richard Saloman highlighted the emerging capability to create globally interacting, digital, special collections in his description of the Early Buddhist Manuscripts Project. These and other presentations demonstrated that real transformation occurs when digital collections are turned over to the users for unexpected interpretation and reuse.

In order to facilitate original and creative knowledge building such as nonconsumptive research, mash-ups, and "citizen science," libraries must do more to establish a stable foundation on which users can work. Large-scale digitization; open access; flexible, minimal, automated metadata; user-friendly 
tools; and effective policy setting can allow user subject experts to participate in exposing collections. Libraries will need to more effectively use existing tools and infrastructure and innovate new solutions where necessary. Greenberg encouraged libraries to "write for Google" and "write for referral" to surface collections in researchers' pathways. Tracy Seneca offered a different twist, reporting on a repurposable method of creating digital archives by harvesting openly accessible Web sites. Speakers gave a wide variety of examples demonstrating how repurposing the context of use provides meaning in a way that is at the heart of the research enterprise. Anne Kenny discussed how special collections can be used to build or enrich digital communities and how passionate those communities become about the digital collaborative space. Yet to enable this knowledge building, libraries must move away from one-off, boutique, digital projects to solidify digital programs. As special collections face the challenges of sustaining digital surrogates and born-digital materials, permanent funding and infrastructure must be allocated to ensure that those collections are accessible and authentic for the long run.

Digitization and digital curation are no longer specialized activities; they are a part of the life-cycle management of special collections. The challenging but critical tasks for success are the policy setting, infrastructure building, and

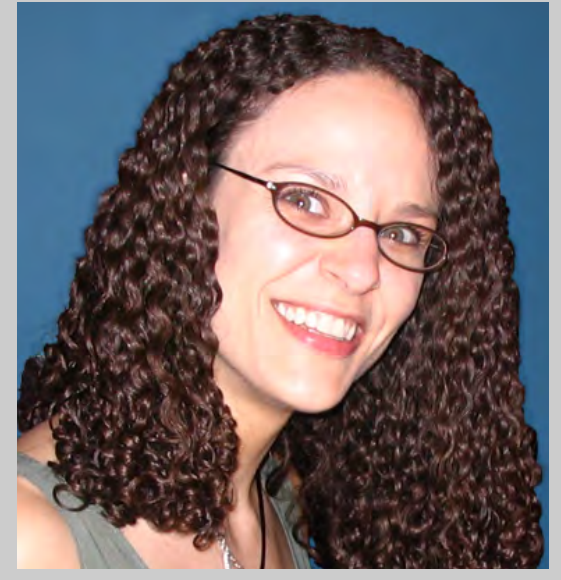

Listen to Katherine Skinner on the need to engage in strong collaborative networks to preserve and expose the digital cultural record. [4 min.] http://www.arl.org/bm doc/rli-267-skinner.mp3 training. Speakers acknowledged that while this work must take place in each library, this work will not be successfully undertaken by libraries acting alone. Throughout the forum, speakers provided concrete examples of successful and innovative collaborations within and across institutions and between institutions and collections users. Kenney advocated for collaborative strategies that bind research libraries together as we work with commercial partners on large-scale digitization of special collections. Greenberg agreed that we must work as a broader, online ecosystem. Waters called for new and reliable ways to link collections across institutional boundaries. Reflecting on the successes of the MetaArchive Cooperative, Katherine Skinner

noted that we need to create durable associations of autonomous entities collaborating to achieve common or compatible goals while maintaining 
flexibility. Competition and protectionist attitudes must give way to institutional humility and stronger collaborative networks. After all, our users do not care which institution owns the original or provides the digital surrogate, they just want unfettered access.

Further, purposeful collaboration takes effort, flexibility, and persistence to achieve the full potential of cooperative activity. Will Noel noted that data management is a major challenge for cooperative efforts, while Skinner added that collaboration demands an organizational structure in order to work. Discussion emphasized that development of infrastructure for collaboration is best kept lightweight, distributed, and virtual, keeping in mind that open, dynamic collaboration is useful for access and exposure, while a closer, constricted organization is necessary to protect and sustain collections. Regardless, consensus confirmed that programmatic digital and collaboration infrastructure are the key investments in effectively connecting researchers with distinctive collections.

\section{Conclusion: An Investment in the Knowledge Economy}

In closing, Ian Wilson reminded the audience that the future of special collections offers opportunities for leadership at the edge of evolving research practice.

Taking advantage of the virtual space is like exploring a new land, where shared risk and calculated investment can result in significant impact. The way scholars learn and process knowledge is changing. Users now commit to search strategies rather than memorization of facts and details. The opportunity to engage the learning process via the raw materials of knowledge, rare objects, and primary sources, is greater than ever before. Moving forward, investment in special collections will require user-centered mission alignment, resource reallocation towards mainstreaming and sustainability, and the commitment and trustintensive work of collaboration; but such an investment offers a rich, rewarding, and transformative contribution to advancing knowledge.

\footnotetext{
Special Collections in ARL Libraries: A Discussion Report from the ARL Working Group on Special Collections (Washington DC: ARL, 2009), http://www.arl.org/bm doc/scwg-report.pdf.

2 An Age of Discovery: Distinctive Collections in the Digital Age, Proceedings from the ARL-CNI Fall Forum, October 14-15, 2009, Washington DC,

http:// www.arl.org/resources/pubs/fallforumproceedings/forum09proceedings.shtml.

3 The Boyer Commission on Educating Undergraduates in the Research University, Reinventing Undergraduate Education: A Blueprint for America's Research Universities (Boyer Commission, 1998), http://naples.cc.sunysb.edu/Pres/boyer.nsf/.
} 


\section{An Age of Discovery: Distinctive Collections in the Digital Age: Proceedings from the ARL-CNI Fall Forum, October 14-15, 2009}

Freely available on the ARL Web site at http://www.arl.org/resources/pubs/fallforumproceedings/forum09proceedings.shtml

Welcoming Remarks

Brinley Franklin, Vice Provost, University of Connecticut, and President, ARL Audio [MP3 2 min.]

Special Collections at the Cusp of the Digital Age: A Credo

Clifford Lynch, Executive Director, CNI

PDF \& Audio [MP3 $5 \mathrm{~min}$.]

Why Are Special Collections So Important? Exploring the Value Proposition of Special Collections Introductory Remarks

Mark Dimunation, Chief of the Rare Book and Special Collections Division, Library of Congress

Audio [MP3 $9 \mathrm{~min}$.]

Why Special Collections Matter Now More than Ever Before

Stephen G. Nichols, Professor of French and Humanities, Medieval French Literature, Johns Hopkins University Audio [MP3 $31 \mathrm{~min}]$

Existential Archives: Looking for the Value Propositions of Archives and Special Collections

Mark A. Greene, Director, American Heritage Center, University of Wyoming

PDF \& Audio [MP3 30 min.]

The Changing Role of Special Collections in Scholarly Communications

Donald J. Waters, Senior Program Officer, Scholarly Communications, The Andrew W. Mellon Foundation PDF \& Audio [MP3 26 min.]

Building on Our Strengths: Opportunities for Special Collections in the Digital Age Introductory Remarks

Nancy E. Gwinn, Director, Smithsonian Institution Libraries

Keynote Remarks: An Age of Discovery: Distinctive Collections in the Digital Age

G. Wayne Clough, Secretary of the Smithsonian Institution PDF \& Audio [MP3 29 min.]

Reactor Comments:

lan E. Wilson, Librarian and Archivist of Canada Emeritus, President of the International Council on Archives,

Strategic Advisor, University of Waterloo Audio [MP3 $10 \mathrm{~min}$.]

Alice Prochaska, University Librarian, Yale University Audio [MP3 8 min.]

\section{Collaboration to Build Cross-Institutional Collections}

Introductory Remarks

Bill Landis, Head of Arrangement and Description \& Metadata Coordinator in Manuscripts and Archives, Yale University Library Audio [MP3 2 min.]

Collaboration to Build Cross-Institutional Collections: Ancient Scrolls and Stone Tablets

Richard Saloman, Professor, Sanskrit and Prakrit Language and Literature, Epigraphy, Ancient Indian History, and

Gandharan Studies, Department of Asian Languages and Literature, University of Washington

Slides [PPS 38.7 MB] \& Audio [MP3 25 min.]

MetaArchive Cooperative: A Collaborative Model for Digital Preservation

Katherine Skinner, Executive Director, Educopia Institute and Program Manager, MetaArchive Cooperative Slides [PPS 3.8 MB] \& Audio [MP3 $27 \mathrm{~min}$.]

Lessons from Two Inter-Institutional Projects: the Islamic Digital Resource Project at the Walters Art Museum and the Archimedes Palimpsest Project

Will Noel, Curator of Manuscripts and Rare Books, Walters Art Museum Audio [MP3 $21 \mathrm{~min}$.] 


\section{Integrating Special Collections into the Enterprise}

Introductory Remarks

Susan K. Nutter, Vice Provost and Director of Libraries, North Carolina State University

Audio [MP3 3 min.]

Integrating Special Collections into the Enterprise: A Case Study of the Yale Center for British Art

Ken Hamma, independent consultant working with the Yale Center for British Art, the Yale Office of Digital Assets and Infrastructure, and the Andrew W. Mellon Foundation; formerly Executive Director for Digital Policy and Initiatives of the J. Paul Getty Trust PDF \& Audio [MP3 $18 \mathrm{~min}$.]

Special Collections in the Digital Age: Partnerships and Collaboration

Fred Heath, Vice Provost and Director, University of Texas Libraries

Slides [PPS 23.2 MB] \& Audio [MP3 27 min.]

\section{Special Collections as Laboratories for Researchers and Students}

Introductory Remarks

Sarah M. Pritchard, University Librarian, Northwestern University

Audio [MP3 4 min.]

Mapping the Stacks: A Guide to Black Chicago's Hidden Archives

Jacqueline Goldsby, Associate Professor, Department of English \& the College, University of Chicago, and

Visiting Associate Professor, Department of English, New York University Audio [MP3 $18 \mathrm{~min}$.]

Archives, Undergraduates, and Active Learning: Case Studies from Yale University Library

Barbara Rockenbach, Director of Undergraduate \& Library Education, Yale University Library

Slides [PPS 3.7 MB] \& Audio [MP3 21 min.]

Student Research on the University, in the Archives, and in the IR

Sarah L. Shreeves, Coordinator, Illinois Digital Environment for Access to Learning and Scholarship (IDEALS),

University of Illinois at Urbana-Champaign

Slides [PPS 4.4 MB] \& Audio MP3 18 min.]

\section{What Changes with Digital Content?}

Introductory Remarks

Clifford Lynch, Executive Director, CNI

What Changes with Digital Content?

Josh Greenberg, Director of Digital Strategy and Scholarship, New York Public Library PDF [13.4 MB]

What Changes with Digital Content? Three Key Issues

Anne R. Kenney, University Librarian, Cornell University PDF \& Slides [PPS 5.2 MB]

\section{What Changes with Digital Content? Web Archiving}

Tracy Seneca, Web Archiving Coordinator, California Digital Library Slides [PPS 2.6 MB]

\section{Concluding Keynote Remarks}

Ian E. Wilson, Librarian and Archivist of Canada Emeritus, President of the International Council on Archives, and Strategic Advisor, University of Waterloo Audio [MP3 26 min.]

Alice Prochaska, University Librarian, Yale University Audio [MP3 $3 \mathrm{~min}$.]

Appendix

Special Collections in ARL Libraries: A Discussion Report from the ARL Working Group on Special Collections, March 2009 PDF

The Unique Role of Special Collections, Special Collections Web Conference, July 7, 2009, Archive 
(C) 2009 Lisa R. Carter

\section{(c) (i) $\$(0)$}

This article is licensed under a Creative Commons Attribution-NoncommercialShare Alike 3.0 United States License. To view a copy of this license, visit http://creativecommons.org/licenses/by-nc-sa/3.0/us/.

To cite this article: Lisa R. Carter. "Moving Special Collections Forward in an Age of Discovery: Themes from the ARL-CNI Forum." Research Library Issues: A Bimonthly Report from ARL, CNI, and SPARC, no. 267 (Dec. 2009): 10-19. http: / / www.arl.org/resources/pubs/rli/archive/rli267.shtml 